\title{
Article
}

\section{From Flat to Nanostructured Photovoltaics: Balance Between Thickness of the Absorber and Charge Screening in Sensitized Solar Cells}

Pablo P. Boix, Yong Hui Lee, Francisco Fabregat-Santiago, Sang Hyuk Im, Ivan Mora-Sero, Juan Bisquert, and Sang II Seok

ACS Nano, Just Accepted Manuscript • DOI: 10.1021/nn204382k • Publication Date (Web): 18 Dec 2011

Downloaded from http://pubs.acs.org on December 20, 2011

\section{Just Accepted}

"Just Accepted" manuscripts have been peer-reviewed and accepted for publication. They are posted online prior to technical editing, formatting for publication and author proofing. The American Chemical Society provides "Just Accepted" as a free service to the research community to expedite the dissemination of scientific material as soon as possible after acceptance. "Just Accepted" manuscripts appear in full in PDF format accompanied by an HTML abstract. "Just Accepted" manuscripts have been fully peer reviewed, but should not be considered the official version of record. They are accessible to all readers and citable by the Digital Object Identifier (DOI®). "Just Accepted" is an optional service offered to authors. Therefore, the "Just Accepted" Web site may not include all articles that will be published in the journal. After a manuscript is technically edited and formatted, it will be removed from the "Just Accepted" Web site and published as an ASAP article. Note that technical editing may introduce minor changes to the manuscript text and/or graphics which could affect content, and all legal disclaimers and ethical guidelines that apply to the journal pertain. ACS cannot be held responsible for errors or consequences arising from the use of information contained in these "Just Accepted" manuscripts. 


\title{
From Flat to Nanostructured Photovoltaics: Balance Between Thickness of the Absorber and Charge Screening in Sensitized Solar Cells
}

\author{
Pablo P. Boix, ${ }^{1}$ Yong Hui Lee, ${ }^{2}$ Francisco Fabregat-Santiago, ${ }^{1}$ Sang Hyuk Im, ${ }^{2}$ Ivan Mora-Sero, ${ }^{1 *}$ \\ Juan Bisquert ${ }^{1}$ and Sang Il Seok ${ }^{2}$ * \\ ${ }^{1}$ Photovoltaic and Optoelectronic Devices Group, Departament de Física, Universitat Jaume I, 12071 \\ Castelló, Spain \\ ${ }^{2}$ Advanced Materials Division, Korea Research Institute of Chemical Technology, 19 Sinseongno, \\ Yuseong, Daejeon 305-600, Republic of Korea \\ *corresponding authors. sero@fca.uji.es, bisquert@ fca.uji.es, seoksi@krict.re.kr
}

\begin{abstract}
Nanoporous metal oxide electrodes provide a high internal area for dye anchoring in dye-sensitized solar cells, but the thickness required to extinguish the solar photons also enhances recombination at the $\mathrm{TiO}_{2} /$ electrolyte interface. The high extinction coefficient of inorganic semiconductor absorber should allow to reduce film thickness improving photovoltage. Here we study all-solid semiconductor sensitized solar cells, in the promising $\mathrm{TiO}_{2} / \mathrm{Sb}_{2} \mathrm{~S}_{3} / \mathrm{P} 3 \mathrm{HT}$ configuration. Flat and nanostructured cells have been prepared and analyzed, developing a cell performance model, based on impedance spectroscopy results, that allows us to determine the impact of the reduction of metal oxide film thickness on the operation of the solar cell. Decreasing effective surface area towards the limit of flat samples, produces a reduction in the recombination rate, increasing the open circuit potential, $V_{o c}$, while providing a significant photocurrent. However, charge compensation problems as a consequence of inefficient charge screening in flat cells increase the hole transport resistance, lowering severely the cell fill factor. The use of novel structures balancing recombination and hole transport will enhance solid sensitized cell performance.
\end{abstract}


Since the first report on dye sensitized solar cells (DSCs), ${ }^{1}$ this research field has experienced an enormous increase. ${ }^{2}$ The success of these cells is based on the use of a new paradigm in comparison with the preexisting photovoltaic technologies. Electron and hole pairs photogenerated in a light absorbing material are quickly transferred to two different transport media. The physical separation of carriers reduces significantly the recombination process, relaxing the quality requirements of the device constituent materials and consequently reducing the production cost. The most common sensitizers used in these devices have been molecular dyes. ${ }^{2}$ As the light absorption step conventionally occurs only in a monolayer of the sensitizer material, the effective area of the device has to be significantly enhanced over the geometrical area in order to improve the light harvesting. Nanostructured photoanodes are used to enhance the effective area and consequently the dye loading. In the most widely used case a liquid electrolyte, containing a regenerative redox couple, is used as hole conductor, as it allows a complete wetting of whole nanostructured effective area.

Obviously the final goal of an applied research is providing a product capable of being industrialized and extensively used, and the sensitized solar cells are not an exception. Aiming at industrial applications, it is favorable to avoid the liquid components of a device. In this sense, the interest on all solid devices has hugely increased in the last years. ${ }^{3,4}$ Currently a big effort is carried out in order to increase the efficiency of these systems. Very recently it has been reported a solid DSC showing an NREL certified $6.08 \%$ efficiency based in an organic dye, C220, and spiro-MeOTAD as hole transporting material, ${ }^{5}$ indicating the progress in this field.

The use of alternative sensitizers to dyes, as inorganic semiconductors, is also one of the hot topics in these technologies. ${ }^{6-10}$ Inorganic semiconductors present a number of characteristics making them very interesting as sensitizers in semiconductor sensitized solar cells or in quantum dot sensitized solar cells (QDSCs), where the semiconductor reduced particle size induces a quantum confinement effect. ${ }^{11}$ Semiconductor QDs present the possibility of band gap tuning, ${ }^{11}$ high extinction coefficient, ${ }^{12,}{ }^{13}$ large intrinsic dipole moments, ${ }^{14}$ and potential processes of multiple exciton generation. ${ }^{15}$ Among these characteristics the high extinction coefficients of semiconductor QDs is especially interesting for the development of all solid sensitized devices. It is known than in solid DSCs using spiro-MeOTAD, as hole transporting material, the recombination rate between electrons in $\mathrm{TiO}_{2}$ and holes in spiro-MeOTAD is significantly higher than in conventional liquid DSCs. ${ }^{16}$ As consequence the thickness of photoanodes in these devices is limited to $\sim 2 \mu \mathrm{m}$. Sensitizers capable of absorbing the sunlight within this restricted thickness are needed, enhancing the interest of the high extinction coefficient of inorganic semiconductor absorbers.

Some years back, the physical mechanisms of carrier transport and accumulation in the DSC were discussed in order to clarify the main factors governing the operation of this device. ${ }^{17-19}$ Short range screening of electrical fields, caused by the combination of nanoscale porous morphology and highly 
concentrated electrolyte has been agreed as a major element of the DSC, facilitating the rise of photovoltage and extraction of carriers with little cost in driving force. The chemical capacitance has become a standard feature of DSC devices, ${ }^{20}$ as an easy way to monitor the rise of the Fermi level of electrons in the screened, metal oxide nanoparticulate medium. However, it must be observed, that the large internal area, produced by nanoporous morphology of relatively thick layers (about $10 \mu \mathrm{m}$ ), imposes a price of enhanced recombination, with the consequent reduction of photovoltage. Therefore a balance must be achieved, between the internal area needed both to accommodate the necessary volume of absorber, and to maintain screening of excess negative and positive photogenerated charges.

Taking advantage of the high extinction coefficient of semiconductors, the electrode structure for all solid QDSCs could be rethinked in order to minimize the recombination process. It has been shown that the reduction of effective surface area decreases recombination, producing an enhancement of open circuit voltage, $V_{o c}$, in liquid QDSCs, as it has been recently shown with electrodes of $\mathrm{ZnO}$ nanowire arrays and Si-ZnO hierarchical structures. ${ }^{21}$ Toyoda et al. ${ }^{22}$ also showed high voltage QDSCs based on inverse opal structure of radius $300 \mathrm{~nm}$, with significantly less internal area than the usual $20 \mathrm{~nm}$ nanoparticulate $\mathrm{TiO}_{2}$ photoelectrodes. The extreme case of effective surface reduction is the use of flat electrodes where the effective surface coincides with the geometrical surface. In this work we compare the solar cell performance of nanostructured (NS) electrodes with flat electrodes in all solid QDSCs. We have prepared $\mathrm{TiO}_{2} / \mathrm{Sb}_{2} \mathrm{~S}_{3} /$ poly(3-hexylthiophene) (P3HT) solid cells with NS and flat configurations, as depicted in Figure 1. We have chosen $\mathrm{Sb}_{2} \mathrm{~S}_{3}$ as semiconductor sensitizer as it has shown significant solar cell performance in all-solid solar cells. ${ }^{23-27}$ Solar cells efficiencies of 5.13\%, under full 1 sun illumination, close to the all solid DSCs efficiencies have been reported using P3HT as hole transporting material (HTM), ${ }^{23}$ highlighting the interest of $\mathrm{TiO}_{2} / \mathrm{Sb}_{2} \mathrm{~S}_{3} / \mathrm{P} 3 \mathrm{HT}$ configuration. We have also analyzed a reference nanostructured cell without $\mathrm{Sb}_{2} \mathrm{~S}_{3}\left(\mathrm{TiO}_{2} / \mathrm{P} 3 \mathrm{HT}\right)$, prepared in the same way that the complete cell but with no semiconductor light absorbing material.

In spite of the interest of the solid approximation for sensitized devices there is relative short number of works modeling their performance. ${ }^{4,16,28-30}$ The development of appropriated models of the physical processes in these devices in mandatory for a focused research that allows further efficiency increase. In addition, the determination of the fundamental parameters governing solar cell performance would be an extraordinary tool for this purpose. Impedance spectroscopy (IS) has been extensively used for the characterization of liquid DSCs ${ }^{31-33}$ and QDSCs. ${ }^{32,34-37}$ Here, we have used IS for modeling all solid $\mathrm{TiO}_{2} / \mathrm{Sb}_{2} \mathrm{~S}_{3} / \mathrm{P} 3 \mathrm{HT}$ in flat and $\mathrm{NS}$ configuration. The results obtained are discussed in terms of fundamentals of all-solid solar cell performance, providing a device picture that could be very helpful to assist the development of solid sensitized solar cells.

\section{Results and Discussion}

Photocurrent generation. Flat and $\mathrm{NS} \mathrm{TiO}_{2} / \mathrm{Sb}_{2} \mathrm{~S}_{3} / \mathrm{P} 3 \mathrm{HT}$, and also reference $\mathrm{TiO}_{2} / \mathrm{P} 3 \mathrm{HT}$, have been 
analyzed by IS at different applied forward bias, $V_{a p p}$, under dark and 1 sun $\left(100 \mathrm{~mW} \mathrm{~cm}{ }^{-2}\right)$ illumination conditions. Impedance measurements also provide the current obtained at each $V_{a p p}$, allowing the construction of current-voltage (J-V) curves in real stationary condition. ${ }^{32} \mathrm{~J}-\mathrm{V}$ curves, under 1 sun illumination obtained for flat and NS devices are plotted in Figure 2. The solar cell parameters extracted from these curves are summarized in Table 1.

NS cell presents higher performance than flat cell due to a higher short circuit current, $J_{s c}$, and fill factor, FF. Converselly $V_{o c}$ is higher for the flat device. It is worth noting that despite the low effective surface area, and consequently lower QD loading of the flat sample, the obtained photocurrent is relatively high, $7.15 \mathrm{~mA} / \mathrm{cm}^{2}$. There are other recent reports relating flat semiconductor sensitized devices. Zaban's group have obtained $J_{s c}=1.86 \mathrm{~mA} / \mathrm{cm}^{2}$, using a flat $\mathrm{SnO}_{2}: \mathrm{F}$ (FTO)/CdSe electrode with polysulfide electrolyte as $\mathrm{HTM}^{38}$ The same group has also proved the tandem concept using flat FTO/CdSe as photoanode and flat FTO/CdS as photocathode. ${ }^{39}$ Very high photocurrents, $J_{s c}=12.95$ $\mathrm{mA} / \mathrm{cm}^{2}$, have been also obtained for FTO/CdSe electrodes, with a $100 \mathrm{~nm}$ thick CdSe, presenting a nanostructure but without any $\mathrm{TiO}_{2} \cdot{ }^{40}$ The performance of flat QDSCs is especially striking when it is compared with the performance of flat DSCs. Recently, flat $\mathrm{TiO}_{2}$ layers as electron acceptor, dye multilayer as donor material and PEDOT:PSS as selective hole contact has demonstrated a maximum photocurrent and efficiency of $1 \mathrm{~mA} / \mathrm{cm}^{2}$ and $\eta=0.30 \%$, respectively, ${ }^{41}$ values sensibly lower than the reported in the present work, see Table 1. The higher extinction coefficient of the semiconductor sensitizer compared with the standard dye N719, as observed in Figure 3, predicts a higher performance of flat QDSCs than flat DSCs. ${ }^{2}$ As mentioned above, this high extinction coefficient, together with the absorption at higher wavelength, allows that very thin films sensitized with $\mathrm{Sb}_{2} \mathrm{~S}_{3}$ produce similar currents than N719 sensitized DSCs made of films with thickness up to 10 times larger. The shape and values of Figure 3 suggest that $\mathrm{Sb}_{2} \mathrm{~S}_{3}$ deposited onto the surface of $\mathrm{TiO}_{2}$ is amorphous rather than crystalline. ${ }^{42}$

Recombination and transport. In order to understand the significant differences observed in the shape of $J-V$ curves for flat and NS cells, impedance spectroscopy measurements have been carried out. A representative example of the complex impedance plots obtained for the analyzed cells is shown in Figure 4. In Figure 4a three different spectra, corresponding to three different values of the applied voltage $V_{a p p}$, obtained for NS sample under dark conditions, are represented. The spectra pattern is composed by two main features one at high frequency and the other one at low frequency. The arc observed at high frequencies is constant independently of the applied bias, see Figure 4b. This fact indicates that it does not depend on Fermi level position and we have ascribed it to the parallel association of the geometrical dielectric capacitance of the cell, $C_{g}$, and the charge transfer resistance at the P3HT-Au interface, $R_{A u}$, that is expected to vary very slowly with voltage.

On the other hand, a close inspection of the low frequency semicircle shows that it is deformed due to the fact that it is composed by two arcs merged, see Figure 4c. Each arc is associated to the parallel 
combination of a Resistance and a Capacitance $(R-C)$. We have ascribed the arc at lowest frequencies with the parallel association between $R_{\text {rec }}$, the recombination resistance of electrons in the $\mathrm{TiO}_{2}$ with holes in P3HT or accepting states in $\mathrm{Sb}_{2} \mathrm{~S}_{3}$, and $C_{\mu}$, the chemical capacitance of electrons in $\mathrm{TiO}_{2}{ }^{20}$ The intermediate frequencies arc, of this second feature, has been ascribed to the parallel association of hole transport resistance along HTM, $R_{H T M}$, and the capacitance of the HTM, $C_{H T M}$. Presumably $C_{H T M}$ has not a single physical origin, at it is the result of several contributions as hole chemical capacitance and/or interfacial capacitances. These assumptions are justified by the previous observations in other all-solid sensitized configuration (concretely $\mathrm{ZnO}$ nanowires/CdSe/CuSCN),${ }^{28}$ and by the physical coherence of final results obtained, as it is discussed below. The equivalent circuit is completed, see Figure 4d, adding a series resistance, $R_{s}$, due to contacts and wires. Solid lines in Figure $4 \mathrm{a}, \mathrm{b}$ and c are the fitting results of the experimental data using the equivalent circuit plotted in Figure 4d. For more accurate fitting, constant phase elements are used instead of ideal capacitances. Note, that the equivalent circuit proposed in Figure $4 \mathrm{~d}$ presents the geometrical capacitance in parallel with the other features, while alternative equivalent circuit consisting in 3 parallel $R$ - $C$ has also the capability of fitting properly the obtained Nyquist plots. The choice of the parallel contribution of $C_{g}$ is due to physical reasons as the geometrical capacitance is affected by the total voltage drop between contact electrodes (removing the voltage drop at the series resistance).

Figure 5 shows $R_{\text {НTM }}, C_{\mu}$ and $R_{\text {rec }}$ obtained from impedance analysis under dark and 1 sun illumination conditions for flat and NS samples. A reference nanostructured sample without $\mathrm{Sb}_{2} \mathrm{~S}_{3}$ has been also analyzed under dark conditions to further evaluate the consistency of the results. $R_{H T M}, C_{\mu}$ and $R_{\text {rec }}$ are plotted against the voltage drop in the sensitized electrode, $V_{F} . V_{F}$ is obtained from the applied bias, $V_{a p p}$, subtracting the voltage drop in the series resistance and counter electrode resistance. ${ }^{32,35}$ Figure 5 is very useful to understand the different trends observed in J-V curves, Figure 2, for flat and NS samples. Hole transport along P3HT introduces a transport resistance that has to be added to $R_{S}$ and $R_{A u}$ to obtain the total series resistance, $R_{\text {series }}=R_{S}+R_{A u}+R_{H T M}$. Flat and NS samples present close values of $R_{H T M}$ at low applied voltage but NS samples present clearly much lower $R_{H T M}$ values as the applied voltage starts to increase, in both dark and illuminated measurements. Using cross-sectioned specimens it was observed by SEM that the thickness of P3HT layer in NS and flat cell was $\sim 20 \mathrm{~nm}$ and $\sim 50 \mathrm{~nm}$, respectively, but the thicker P3HT layer observed in flat samples is not enough to explain the large difference in the $R_{H T M}$ obtained between flat and nanostructured cells, as we discuss below. The higher $R_{H T M}$ is the main reason for the lower FF found for flat cells. ${ }^{32}$ If this resistor could be eliminated, FF would rise up to 0.49 increasing efficiency to $2 \%$. The other reason for the poor shape in the $J-V$ curve is the relatively low value of $R_{\text {rec }}$ under illumination at low potentials $\left(\sim 100 \Omega \mathrm{cm}^{2}\right)$ that produces a loss in photocurrent instead of the plateau like shape as in the NS sample. Conversely, at potentials larger than $0.4 \mathrm{~V}$ under illumination, $R_{\text {rec }}$ is higher for flat samples than for NS cells, and consequently the $V_{o c}$ obtained in flat samples is higher than that for NS cells. ${ }^{21,32}$ The reduction of the effective surface area produces a 
decrease in the recombination rate, ${ }^{21}$ taking into account that the recombination rate is inversely proportional to $R_{\text {rec }}{ }^{32}$ It is also remarkable the lower slope found for $R_{\text {rec }}$ as a function of $V_{F}$ in the flat electrode sample which also contributes to the low FF. ${ }^{32}$

Figure SI1 represents an analogous figure to Figure 5 under dark conditions but adding the results obtained for an additional NS solar cell prepared in the same conditions. Figure SI1 indicate that the obtained IS results are reproducible and characteristic of this type of cells.

Note that in this discussion we have only considered the series resistance introduced by the transport of holes along HTM and the transport of electrons along $\mathrm{TiO}_{2}$ is not considered at all, due to two reasons. First transport resistance of electrons along $\mathrm{TiO}_{2}$ nanostructured electrode cannot be determined from the impedance spectra obtained for the analyzed cells, Figure 4. The straight line part of the transmission line from which this transport resistance is obtained in the liquid sensitized solar cells, ${ }^{32}$ is not visible in this cas. The time constants of arcs related with hole transport and recombination are very close producing a high overlaping of the two arcs that hides the straight line feature. On the other hand, electron transport resistance decreases exponentially with $V_{a p p}$ being significantly low at high $V_{a p p}$ (where the FF is mainly determined). ${ }^{32,}{ }^{35}$ The contribution of electron transport resistance to solar cell performance can be neglected in comparison with the hole contribution.

It is also very interesting to compare the results obtained from nanostructured samples with and without $\mathrm{Sb}_{2} \mathrm{~S}_{3}$ light absorbing layer, see Figures 5 and $\mathrm{SI} 1$, to obtain significant clues to understand the recombination process in these cells. NS cell without $\mathrm{Sb}_{2} \mathrm{~S}_{3}$ presents higher recombination resistance that the complete NS cell with $\mathrm{Sb}_{2} \mathrm{~S}_{3}$ absorber. Similar behavior has been also observed for $\mathrm{Sb}_{2} \mathrm{~S}_{3}$ all solid solar cells using CuSCN as HTM. ${ }^{29}$ As it has been observed that $\mathrm{Sb}_{2} \mathrm{~S}_{3}$ does not form a continuous layer on $\mathrm{TiO}_{2}$ (i.e. there is a direct contact between $\mathrm{TiO}_{2}$ and $\mathrm{P} 3 \mathrm{HT}$ even in the presence of $\mathrm{Sb}_{2} \mathrm{~S}_{3}$ ), ${ }^{27}$ the main recombination pathway of electrons in $\mathrm{TiO}_{2}$, in the analyzed cells, is between $\mathrm{TiO}_{2}$ and $\mathrm{Sb}_{2} \mathrm{~S}_{3}$. In fact, it seems to be the general behavior for $\mathrm{Sb}_{2} \mathrm{~S}_{3}$ cells taking in account the previous results on $\mathrm{CuSCN}^{29} \mathrm{Sb}_{2} \mathrm{~S}_{3}$ induces efficient recombination pathways, this recombination has to be avoided in order to improve the $V_{o c}$ reported for these cells and consequently their efficiencies.

Capacitance and screening. In order to understand the physical processes that occur on a device is especially interesting to analyze the behavior of capacitance. Considering the chemical capacitance of electrons in $\mathrm{TiO}_{2}$, another significant difference can be observed between flat and NS cells. In the case of flat cells $\mathrm{C}_{\mu}$ does not rise exponentially with $V_{F}$ as it should be expected from the variation of Fermi level with the applied voltage. ${ }^{20}$ In contrast, an exponential increase of $C_{\mu}$ is observed for NS solar cell under 1 sun illumination at high $V_{F}$, see Figure 5. This difference points to a different scenario in both cells affecting solar cell performance.

Figure 6, presents three schemes of different cell configurations that will be useful to discuss the fundamental differences between all solid flat and NS solar cells. Figure 6a presents a cartoon of a conventional DSC. In DSCs, due to the high concentration of supporting electrolyte species, in the order 
of $\mathrm{c}=10^{20} \mathrm{~cm}^{-3}$, it is possible to inject electrons from the substrate to the $\mathrm{TiO}_{2}$ by applying voltage and maintain charge neutrality in the nanostructured film, as the high concentration of compensating ions in the electrolyte screens the injected electrons. In this case, the electron concentration, at high voltage in the solar cell, is substantially lower than the electrolyte species and therefore, no charge compensation problem is detected in liquid DSCs. An equivalent situation can be obtained by electron injection from the dye by photoexcitation, than in the case of electrons supplied from the contact by the application of a forward bias. ${ }^{31}$ In both cases the electron Fermi level raises easily aided by charge screening by the electrolyte. Under dark conditions in equilibrium, the electron Fermi level in $\mathrm{TiO}_{2}, E_{F 0}$, aligns with the electrolyte redox potential, $E_{\text {redox }}$, see Figure 6a. When a voltage is applied on $\mathrm{TiO}_{2}$, or photogenerated electrons are injected, the electron density in $\mathrm{TiO}_{2}$ increases, shifting the electron Fermi level, $E_{F n}$, up. As the initial concentrations in the electrolyte are not significantly modified, the $E_{\text {redox }}$ remains unchanged. Thus, under illumination $V_{o c}$ is the difference between $E_{F n}$ and $E_{\text {redox }}$, see Figure 6a.

In the case of all solid NS $\mathrm{TiO}_{2} / \mathrm{Sb}_{2} \mathrm{~S}_{3} / \mathrm{P} 3 \mathrm{HT}$ solar cell, the number of holes in the dark in p-doped $\mathrm{P} 3 \mathrm{HT}$ is likely much less than the number of electrons reclaimed by $\mathrm{TiO}_{2}$ to raise the voltage, in the order of $\mathrm{c}=10^{15}-10^{16} \mathrm{~cm}^{-3}$. Therefore NS all solid solar cells present high $R_{\text {HTM }}$ under dark and low applied voltage. However, photogeneration of electron-hole pairs in the absorber creates both electrons in $\mathrm{TiO}_{2}$ and equal amount of holes in P3HT. The Fermi levels now separate and the film is homogeneously charged as manifest in the increase of the chemical capacitance, see Figure 5. On the other hand, note that for NS cell under 1 sun illumination the $R_{\text {НTM }}$ decreases with $V_{F}$. This decrease becomes faster at $V_{F} \sim 0.4$ $\mathrm{V}$, the same value at which begins to grow exponentially the chemical capacitance of electrons in the NS cell, see Figure 6 . In addition the capacitance $C_{H T M}$, Figure SI2, increases exponentially at $V_{F} \sim 0.4 \mathrm{~V}$ indicating that $C_{\text {HTM }}$ is governed by the hole chemical capacitance in P3HT at $V_{F}>0.4$ V. $R_{\text {HTM }}$ is inversely proportional to the hole density in the hole transporting material (i.e. P3HT conductivity is directly proportional to the hole density). ${ }^{28}$ Then the decrease of $R_{\text {HTM }}$ with illumination can be attributed to an uniform increase of hole density in P3HT, and consequently the hole Fermi level at P3HT, $E_{F p}$, moves down as the density of holes has been significantly modified from the dark equilibrium conditions, in contrast with the case of liquid DSCs, see Figure $6 \mathrm{~b}$. In this case the $V_{o c}$ is determined as $E_{F n}-E_{F p}$. Under illumination there are enough holes, photoinjected into P3HT from $\mathrm{Sb}_{2} \mathrm{~S}_{3}$, to compensate the electrons in $\mathrm{TiO}_{2}$, in addition the nanostructure architecture of the cells allows that the holes are relatively close to electrons. Both species mutually screen and compensate their charge, see Figure 6b. Under dark conditions, at low applied voltage the hole density is very low and consequently $R_{\text {НTM }}$ presents a high value for NS structured samples. As the applied voltage increases holes are injected in P3HT enhancing its conductivity and decreasing the $R_{H T M}$ value for NS samples. This is possible due to the nanostructured architecture that allows an efficient screening of the injected electrons and holes, permitting a significant increase of the hole density.

Finally, in the planar configuration, mutual charge screening by photogenerated carriers of opposite 
sign is not possible, as the electrons and holes become confined in spatially separated media due to the layered architecture, see Figure 6c. The density of carriers in $\mathrm{TiO}_{2}$ and $\mathrm{P} 3 \mathrm{HT}$ are not uniform along the separate layers. Each material layer results in different charge distribution in the semiconductors, including band bending at interfaces. An efficient screening and compensation of charges cannot be attained and chemical capacitance cannot be enhanced, because capacitance is affected by bandbending and dielectric effects. Note that associated with the changes in the charge density and distribution observed in the capacitance of planar and NS electrodes, are the shapes and values of $R_{\text {rec }}$ of Figure 5 . Thus rising the electron density in $\mathrm{TiO}_{2}$ produces an equivalent decrease in $R_{\text {rec }}$. The lower density of holes in P3HT produces higher $R_{H T M}$ values than in the case of NS cells, especially under dark conditions at high applied bias where no photoinjected holes are present, and the inefficient charge screening does not allow the hole injection, as in the case of NS samples, as electron counterparts cannot screen them. Conversely, the higher charge separation between electrons and holes reduces the recombination rate, as shown in figure 5 at the higher potentials, yielding to the higher $V_{o c}$ observed in Figure 2.

\section{Conclusion}

In summary, the higher extinction coefficient of inorganic semiconductors allows a higher versatility in the electrode architecture of sensitized cells than in the case of conventional DSCs. The reduction of the effective surface area reduces the cell recombination, but impedes the screening and charge compensation effect of holes in the solid hole transporting media. This effect is significant in all solid devices as the concentration of holes is significantly lower than in a liquid electrolyte. The final consequence is an increase of hole transport resistance in the HTM, affecting the total series resistance of the cell and reducing the FF. This work emphasizes the fundamentals of cell performance, indicating that a balance between effective surface area and screening effect is needed for an optimized cell operation, with a reduced recombination and efficient hole transport. In addition, this balance will depend on the type of hole transporting material used. The development of hole transporting material with improved transport and screening characteristics will undoubtedly enhance the current all solid semiconductor sensitized cells, that present higher potentially for the development of high efficient solid devices than solid DSCs.

\section{Materials and Methods}

Solar Cell Preparation. The flat and nanostructured cells for impedance spectroscopy analysis were prepared as follows. A $50 \mathrm{~nm}$ dense $\mathrm{TiO}_{2}$ layer was deposited on a patterned FTO coated glass substrate by spraying $0.02 \mathrm{M}$ solution of titanium diisopropoxide bis(acetylacetonate) at $450{ }^{\circ} \mathrm{C}$ (flat electrode). For NS samples, a $1.0 \mu \mathrm{m}$ porous $\mathrm{TiO}_{2}$ layer was then coated onto some of the flat electrodes by screenprinting method using $\mathrm{TiO}_{2}$ paste and followed by heat-treatment at $500{ }^{\circ} \mathrm{C}$ for $1 \mathrm{~h}$ in air atmosphere, as reported previously ${ }^{23}$ (nanostructured electrode). Here $\mathrm{TiO}_{2}$ particles of about $60 \mathrm{~nm}$ diameter for $\mathrm{TiO}_{2}$ 
paste were synthesized by hydrothermal treatment at $250{ }^{\circ} \mathrm{C}$ for $12 \mathrm{~h}$ using a peroxotitanium complex solution. The two type of electrodes were immersed into a solution mixture of $\mathrm{SbCl}_{3} /$ acetone $(0.65 \mathrm{~g} / 2.5$ $\mathrm{mL}$ ), $25 \mathrm{~mL}$ of a $1 \mathrm{M} \mathrm{Na}_{2} \mathrm{~S}_{2} \mathrm{O}_{3}$ solution, and $75 \mathrm{~mL}$ of deionized water for $3 \mathrm{~h}^{43}$ The resulting $\mathrm{Sb}_{2} \mathrm{~S}_{3^{-}}$ coated electrodes were annealed at $300{ }^{\circ} \mathrm{C}$ in an argon (Ar) atmosphere. For reference NS sample with no $\mathrm{Sb}_{2} \mathrm{~S}_{3}$ deposited this step is skipped. Both the flat and nanostructured devices were spin-coated at 2500 rpm for $60 \mathrm{~s}$ with a regioregular-P3HT (Poly-3-hexylthiophene) solution (Reike Metals Co. $15 \mathrm{mg} / \mathrm{mL}$ in 1,2-dichlorobenzene). As a counter electrode, Au was deposited by thermal evaporator under a pressure of $5 \times 10^{-5}$ Torr, giving an active area of $16 \mathrm{~mm}^{2}$ for each device.

Solar Cell Characterization. The cells were illuminated using a solar simulator at AM1.5 G, where the light intensity was adjusted with an NREL-calibrated Si solar cell with a KG-5 filter to 1 sun of intensity $\left(100 \mathrm{~mW} / \mathrm{cm}^{2}\right)$. Impedance measurement were carried out with a FRA-equipped PGSTAT-30 from Autolab, applying a $20 \mathrm{mV}$ AC signal and scanning in a frequency range between $400 \mathrm{kHz}$ and 0.1 $\mathrm{Hz}$ at different forward applied bias. IS was carried out in dark and 1 sun illumination conditions. Light measurements were carried out using a metallic mask of $0.13 \mathrm{~cm}^{2}$. Current data for $\mathrm{J}-\mathrm{V}$ curves has been obtained from impedance measurements at each applied voltage.

\section{Acknowlegements}

This study was supported by the Global Research Laboratory (GRL) Program through the National Research Foundation of Korea funded by the Ministry of Education, Science and Technology, and a grant from KRICT 2020 Program for future Technology of Korea Research Institute of Chemical Technology (KRICT), Republic of Korea, the Ministerio de Educación y Ciencia of Spain under the projects HOPE CSD2007-00007 (Consolider-Ingenio 2010), JES-NANOSOLAR PLE2009-0042, and MAT 2010-19827 and by Generalitat Valenciana project PROMETEO/2009/058.

Supporting Information Available: Reproducibility of the IS results analyzing different cells and $C_{H T M}$ under illumination. This material is available free of charge via the Internet at http://pubs.acs.org. 
References

1. O' Regan, B.; Grätzel, M., A Low-Cost High-Efficiency Solar Cell Based on Dye-Sensitized Colloidal $\mathrm{TiO}_{2}$ Films. Nature 1991, 353, 737-740.

2. $\quad$ Peter, L. M., The Grätzel Cell: Where Next? J. Phvs. Chem. Lett. 2011, 2, 1861-1867.

3. Bach, U.; Lupo, D.; P Comte, P.; Moser, J. E.; Weissörtel, F.; Salbeck, J.; Spreitzer, H.; Grätzel, M., Solid-State Dye-Sensitized Mesoporous $\mathrm{TiO}_{2}$ Solar Cells with High Photon-to-Electron Conversion Efficiencies. Nature 1998, 398, 583-585.

4. Wang, M.; Liu, J.; Cevey-Ha, N.-L.; Moon, S.-J.-.; Liska, P.; Humphry-Baker, R.; Moser, J.-E.; Grätzel, C.; Wang, P.; Zakeeruddin, S. M.; Grätzel, M., High Efficiency Solid-State Sensitized Heterojunction Photovoltaic Device. Nano Todav 2010, 5, 169-174.

5. $\quad$ Cai, N.; Moon, S.-J.; Cevey-Ha, L.; Moehl, T.; Humphry-Baker, R.; Wang, P.; Zakeeruddin, S. M.; Grätzel, M., An Organic D- $\pi$-A Dye for Record Efficiency Solid-State Sensitized Heterojunction Solar Cells. Nano Lett. 2011, 11, 1452-1456.

6. Hodes, G., Comparison of Dye- and Semiconductor-Sensitized Porous Nanocrystalline Liquid Junction Solar Cells. J. Phvs. Chem. C 2008, 112, 17778-17787.

7. Kamat, P. V., Quantum Dot Solar Cells. Semiconductor Nanocrystals as Light Harvesters. $J$. Phvs. Chem. C 2008, 112, 18737-18753.

8. Kamat, P. V.; Tvrdy, K.; Baker, D. R.; Radich, J. G., Beyond Photovoltaics: Semiconductor Nanoarchitectures for Liquid-Junction Solar Cells. Chem. Rev. 2010, 110, 6664-6688.

9. Mora-Seró, I.; Bisquert, J., Breakthroughs in the Development of Semiconductor-Sensitized Solar Cells. J. Phvs. Chem. Lett. 2010, 1, 3046-3052.

10. Rühle, S.; Shalom, M.; Zaban, A., Quantum-Dot-Sensitized Solar Cells. Chem. Phys. Chem. 2010, 11, 2290-2304.

11. Alivisatos, A. P., Semiconductor Clusters, Nanocrystals, and Quantum Dots. Science 1996, 271, 933-937.

12. Sun, J.; Goldys, E. M., Linear Absorption and Molar Extinction Coefficients in Direct Semiconductor Quantum Dots. J. Phys. Chem. C 2010, 112, 9261-9266.

13. Yu, W.; Qu, L. H.; Guo, W. Z.; Peng, X. G., Experimental Determination of the Extinction Coefficient of CdTe, CdSe, and CdS Nanocrystals. Chem. Mater. 2003, 15, 2854-2860.

14. Hanewinkel, B.; Knorr, A.; Thomas, P.; Koch, S. W., Optical Near-Field Response of Semiconductor Quantum Dots. Phvs. Rev. B 1997, 55, 13715-13725.

15. Sambur, J. B.; Novet, T.; Parkinson, B. A., Multiple Exciton Collection in a Sensitized Photovoltaic System. Science 2010, 330, 63-66.

16. Fabregat-Santiago, F.; Bisquert, J.; Cevey, L.; Chen, P.; Wang, M.; Zakeeruddin, S. M.; Grätzel, M., Electron Transport and Recombination in Solid-State Dye Solar Cell with Spiro-OMeTAD as Hole 
Conductor. J. Am. Chem. Soc. 2009, 131, 558-562.

17. Zaban, A.; Meier, A.; Gregg, B. A., Electric Potential Distribution and Short Range Screening in Nanoporous $\mathrm{TiO}_{2}$ Electrodes. J.Phvs. Chem. B 1997, 101, 7985-7990.

18. Schwarzburg, K.; Willig, F., Origin of Photovoltage and Photocurrent in the Nanoporous DyeSensitized Electrochemical Solar Cell. J. Phys. Chem. B 1999, 28, 5743-5746.

19. Pichot, F.; Gregg, B. A., The Photovoltage-Determining Mechanism in Dye-Sensitized Solar Cells. J.Phvs. Chem. B 2000, 104, 6-10.

20. Bisquert, J., Chemical Capacitance of Nanostructured Semiconductors: Its Origin and Significance for Heterogeneous Solar Cells. Phys. Chem. Chem. Phys. 2003, 5, 5360-5364.

21. Sudhagar, P.; Song, T.; Lee, D. H.; Mora-Seró, I.; Bisquert, J.; Laudenslager, M.; Sigmund, W. M.; Park, W. I.; Paik, U.; Kang, Y. S., High Open Circuit Voltage Quantum Dot Sensitized Solar Cells Manufactured with $\mathrm{ZnO}$ Nanowire Arrays and $\mathrm{Si} / \mathrm{ZnO}$ Branched Hierarchical Structures. J. Phys. Chem. Lett. 2011, 2, 1984-1990.

22. Diguna, L. J.; Shen, Q.; Kobayashi, J.; Toyoda, T., High Efficiency of CdSe Quantum-DotSensitized $\mathrm{TiO}_{2}$ Inverse Opal Solar Cells. Appl. Phvs. Lett. 2007, 91, 023116.

23. Chang, J. A.; Rhee, J. H.; Im, S. H.; Lee, Y. H.; Kim, H.-J.; Seok, S. I.; Nazeeruddin, M. K.; Grätzel, M., High-Performance Nanostructured Inorganic-Organic Heterojunction Solar Cells. Nano Lett. 2010, 10, (7), 2609-2612.

24. Choné, C.; Larramona, G., French Patent 2899385, 05, October 2007.

25. Itzhaik, Y.; Niitsoo, O.; Page, M.; Hodes, G., $\mathrm{Sb}_{2} \mathrm{~S}_{3}$-Sensitized Nanoporous TiO2 Solar Cells. $J$. Phvs. Chem.C 2009, 113, 4254-4256.

26. Moon, S.-J.; Itzhaik, Y.; Yum, J.-H.; Zakeeruddin, S. M.; Hodes, G.; Grätzel, M., $\mathrm{Sb}_{2} \mathrm{~S}_{3}$-Based Mesoscopic Solar Cell using an Organic Hole Conductor. J. Phvs. Chem. Lett. 2010, 1, 1524-1527.

27. Nezu, S.; Larramona, G.; Chon, C.; Jacob, A.; Delatouche, B.; Péré, D.; Moisan, C., Light Soaking and Gas Effect on Nanocrystalline TiO2/Sb2S3/CuSCN Photovoltaic Cells following Extremely Thin Absorber Concept. J. Phvs. Chem. C 2010, 114, 6854-6859.

28. Mora-Seró, I.; Giménez, S.; Fabregat-Santiago, F.; Azaceta, E.; Tena-Zaera, R.; Bisquert, J., Modeling and Characterization of Extremely Thin Absorber (eta) Solar Cells Based on ZnO Nanowires. Phvs. Chem. Chem. Phvs. 2011, 13, 7162-7169.

29. Boix, P. P.; Larramona, G.; Jacob, A.; Delatouche, B.; Mora-Seró, I.; Bisquert, J., Hole Transport and Recombination in All-Solid $\mathrm{Sb}_{2} \mathrm{~S}_{3}$-Sensitized $\mathrm{TiO}_{2}$ Solar Cells Using CuSCN As Hole Transporter. J. Phvs. Chem.C 2011, DOI: 10.1021/jp210002c.

30. Weickert, J.; Auras, F; Bein, T.; Schmidt-Mende, L., Characterization of Interfacial Modifiers for Hybrid Solar J. Phvs. Chem. C 2011, 115, 15081-15088.

31. Fabregat-Santiago, F.; Bisquert, J.; Garcia-Belmonte, G.; Boschloo, G.; Hagfeldt, A., Influence of Electrolyte in Transport and Recombination in Dye-Sensitized Solar Cells Studied by Impedance 
Spectroscopy. Sol. Energ. Mat. Sol.C. 2005, 87, 117-131.

32. Fabregat-Santiago, F.; Garcia-Belmonte, G.; Mora-Seró, I.; Bisquert, J., Characterization of Nanostructured Hybrid and Organic Solar Cells by Impedance Spectroscopy. Phys. Chem. Chem. Phys. 2011, 13, 9083-9118.

33. Wang, Q.; Ito, S.; Grätzel, M.; Fabregat-Santiago, F.; Mora-Seró, I.; Bisquert, J.; Bessho, T.; Imai, H., Characteristics of High Efficiency Dye-Sensitized Solar Cells. J. Phys. Chem. C 2006, 110, 25210-25221.

34. Braga, A.; Giménez, S.; Concina, I.; Vomiero, A.; Mora-Seró, I., Panchromatic Sensitized Solar Cells Based on Metal Sulfide Quantum Dots. J.Phvs. Chem. Lett. 2011, 2, 454-460.

35. Gónzalez-Pedro, V.; Xu, X.; Mora-Seró, I.; Bisquert, J., Modeling High-Efficiency Quantum Dot Sensitized Solar Cells. ACS Nano 2010, 4, 5783-5790.

36. Hossain, M. A.; Jennings, J. R.; Koh, Z. Y.; Wang, Q., Carrier Generation and Collection in $\mathrm{CdS} / \mathrm{CdSe}$-Sensitized $\mathrm{SnO}_{2}$ Solar Cells Exhibiting Unprecedented Photocurrent Densities. ACS Nano 2011, 5, 3172-3181.

37. Lee, H. J.; Wang, M.; Chen, P.; Gamelin, D. R.; Zakeeruddin, S. M.; Grätzel, M.; Nazeeruddin, M. K., Efficient CdSe Quantum Dot-Sensitized Solar Cells Prepared by an Improved Successive Ionic Layer Adsorption and Reaction Process. Nano Lett. 2009, 9, 4221-4227.

38. Shalom, M.; Tachan, Z.; Bouhadana, Y.; Barad, H.-N.; Zaban, A., Illumination IntensityDependent Electronic Properties in Quantum Dot Sensitized Solar Cells. J. Phys. Chem. Lett. 2011, 2, 1998-2003.

39. Shalom, M.; Hod, I.; Tachan, Z.; Buhbut, S.; Tirosh, S.; Zaban, A., Quantum Dot Based Anode and Cathode for High Voltage Tandem Photo-Electrochemical Solar Cell. Energ. Environ. Science 2011, 4, 1874-1878.

40. Lai, C.-H.; Chou, P.-T., All Chemically Deposited, Annealing and Mesoporous Metal Oxide Free Cdse Solar Cells. Chem. Commun. 2011, 47, 3448-3450.

41. Unger, E. L.; Ripaud, E.; Leriche, P.; Cravino, A.; Roncali, J.; Johansson, E. M. J.; Hagfeldt, A.; Boschloo, G., Bilayer Hybrid Solar Cells Based on Triphenylamine-Thienylenevinylene Dye and $\mathrm{TiO}_{2}$. J Phvs. Chem.C 2010, 114, 11659-11664.

42. Versavel, M. Y.; Haber, J. A., Structural and Optical Properties of Amorphous and Crystalline Antimony Sulfide Thin-Films. Thin Solid Films 2007, 515, 7171-7176.

43. Messina, S.; Nair, M. T. S.; Nair, P. K., Antimony Sulfide Thin Films in Chemically Deposited Thin Film Photovoltaic Cells. Thin Solid Films 2007, 515, 5777-5782. 


\section{Figure legends}

Figure 1: Schematic illustration of device structures for (a) nanostructured and (b) flat cell. The meaning of the abbreviations used is: d: dense; ns: nanostructured; P3HT: Poly-3-hexylthiophene.

Figure 2: Current-Potential curve extracted from impedance spectroscopy measurements for flat and nanostructured configurations, under 1 sun (1.5 AM G) illumination.

Figure 3: Extinction coefficient of $\mathrm{N} 719$ and $\mathrm{Sb}_{2} \mathrm{~S}_{3}$ absorbers. $\mathrm{Sb}_{2} \mathrm{~S}_{3}$ presents both a larger absorption and also a smaller bandgap than N719.

Figure 4: Nyquist plots of $\mathrm{NS} \mathrm{TiO}_{2} / \mathrm{Sb}_{2} \mathrm{~S}_{3} / \mathrm{P} 3 \mathrm{HT}$ solar cell measured under dark conditions. (a) Nyquist plots at three different applied bias. (b) Zoom of a) at high frequency region. (c) Nyquist plot at $V_{a p p}=0.50 \mathrm{~V}$, the frequencies at which different points were measured are included in the graph. (d) Equivalent circuit employed to fit the Nyquist plots. Solid lines in (a), (b) and (c) are the fittings of the experimental data using the model in (d).

Figure 5: Hole transport resistance, $R_{H T}$, Chemical capacitance of electrons in $\mathrm{TiO}_{2}, \mathrm{C}_{\mu}$, and recombination resistance, $R_{\text {rec }}$, of nanostructured and flat $\mathrm{TiO}_{2} / \mathrm{Sb}_{2} \mathrm{~S}_{3} / \mathrm{P} 3 \mathrm{Hta}$ s function of potential $V_{F}$, measured under dark and 1 sun illumination.

Figure 6: Scheme of nanostructured (a) (b) and planar (c) solar cells. (a) The classic Grätzel cell formed by dyed nanostructured $\mathrm{TiO}_{2}$ permeated with a redox $\mathrm{I}^{-} / \mathrm{I}_{3}^{-}$electrolyte. Due to high concentration of supporting electrolyte species, it is possible to inject electrons from the substrate by applied voltage maintaining charge neutrality in the nanostructured film. The electron concentration, at high voltage in the solar cell, is substantially less than the electrolyte species. The same situation can be obtained by electron injection form the dye by photoexctitation. In both cases the electron Fermi level raises easily aided by charge screening by the electrolyte. (b) Nanostructured $\mathrm{TiO}_{2} / \mathrm{Sb}_{2} \mathrm{~S}_{3} / \mathrm{P} 3 \mathrm{HT}$ solid solar cell. In this case the number of holes in the dark in $\mathrm{P} 3 \mathrm{HT}$ is likely much less than the number of electrons reclaimed by $\mathrm{TiO}_{2}$ to raise the voltage. Injection of holes from the contact is also unlikely. Therefore charging the nanostructured film in the dark is difficult. However, photogeneration of electron-hole pairs in the absorber creates both electrons in $\mathrm{TiO}_{2}$ and equal amount of holes in P3HT. The Fermi levels now separate and the film is homogeneously charged as manifest in the increase of the chemical capacitance. (c) In the planar configuration, charge screening by photogenerated carriers of opposite sign is not possible. Each material layer obtains different conditions of charge distribution including band bending at interfaces. 
Table 1: Solar cell parameters of flat and nanostructured cells analyzed in Figure 2. 
(a)

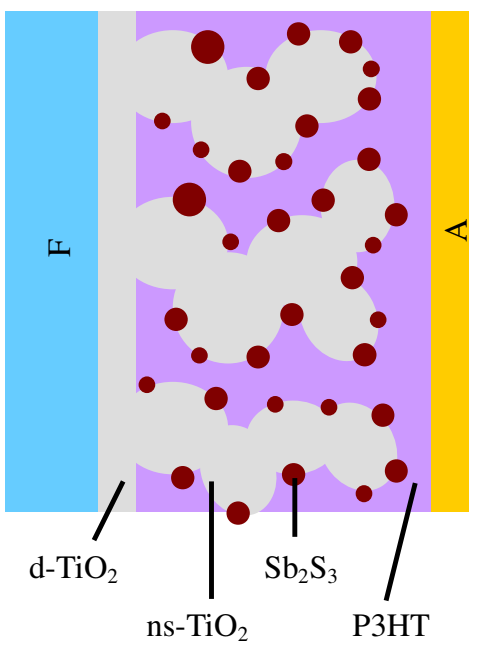

(b)

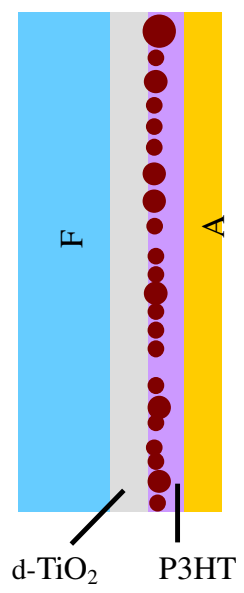

Fig. 1 
Fig. 2

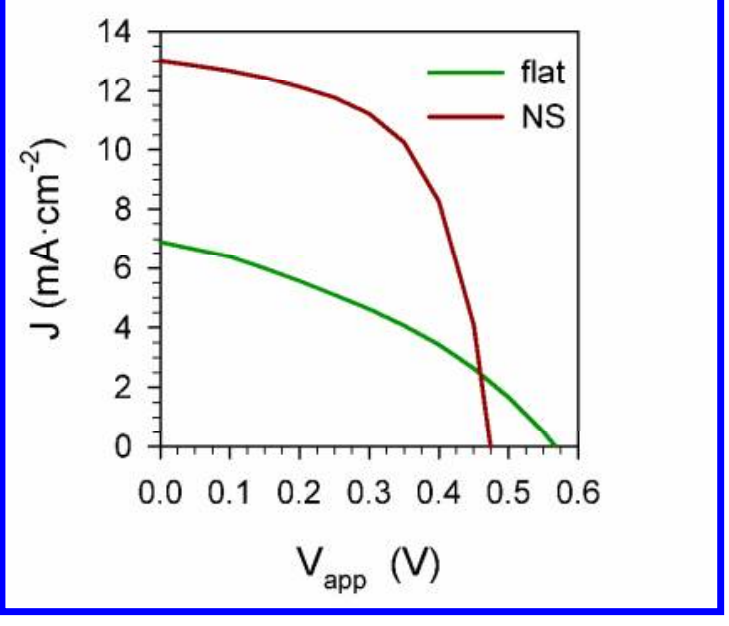


Fig. 3

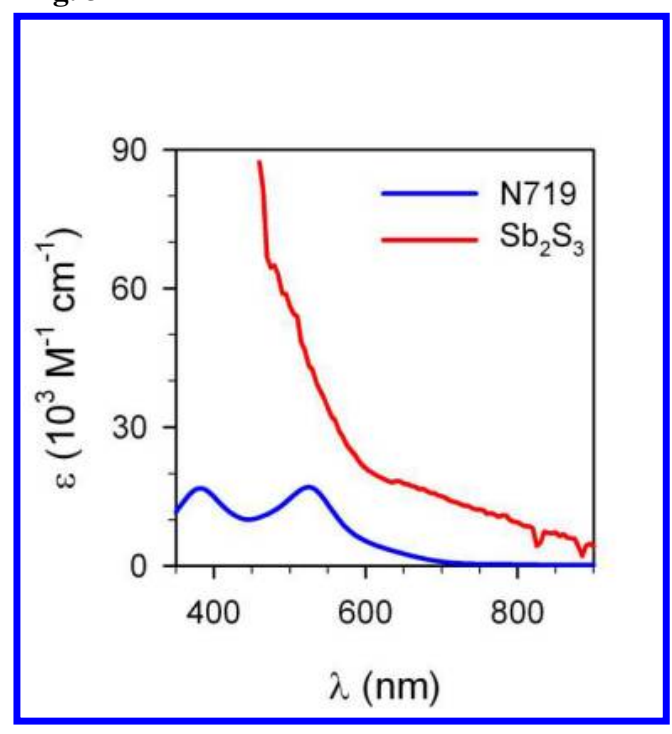

26

27

28

29

30

31

32

33

34

35

36

37

38

39

40

41

42

43

44

45

46

47

48

49

50

51

52

53

54

55

56

57

58

59

60 
Fig. 4

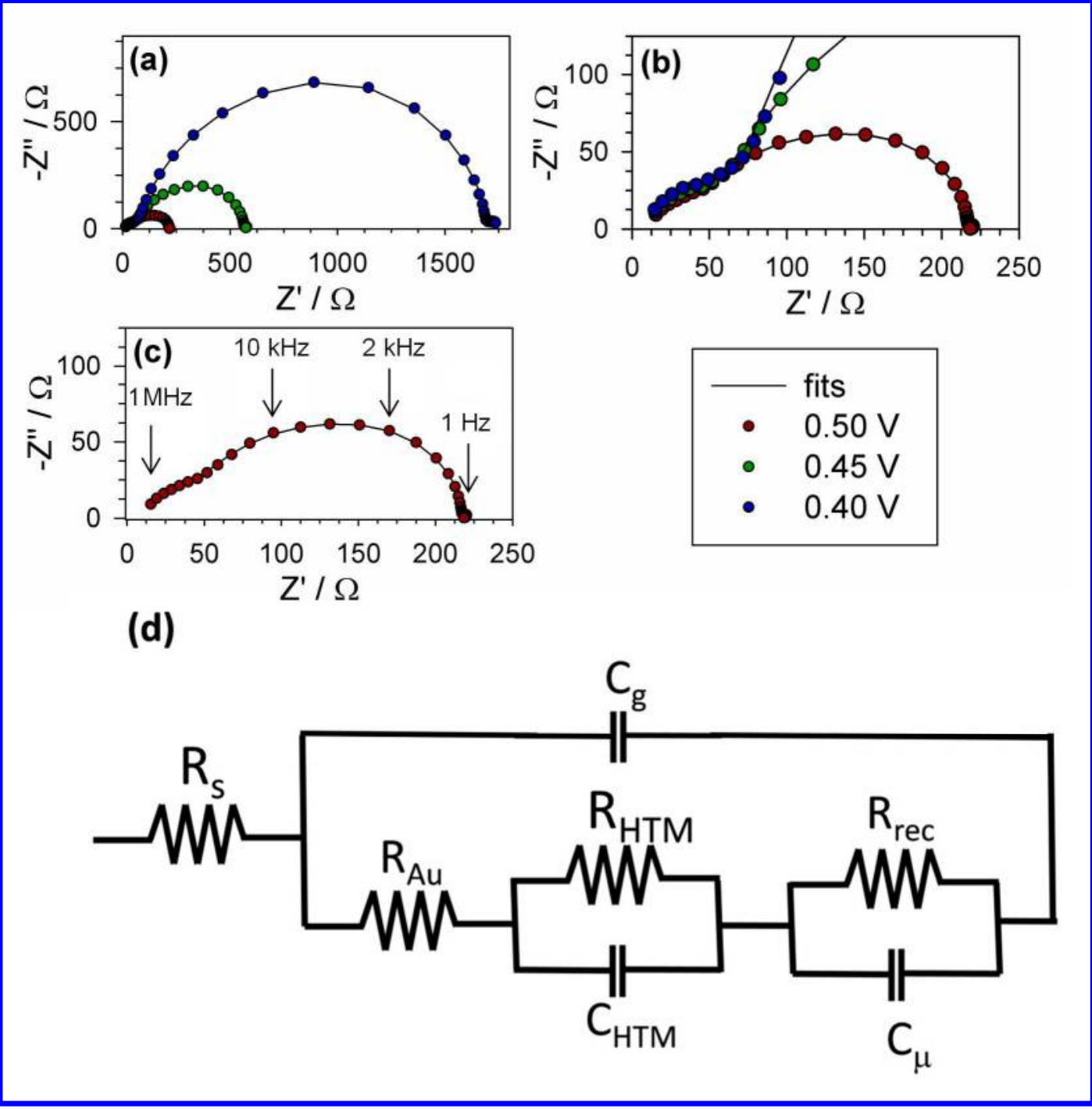


Fig. 5

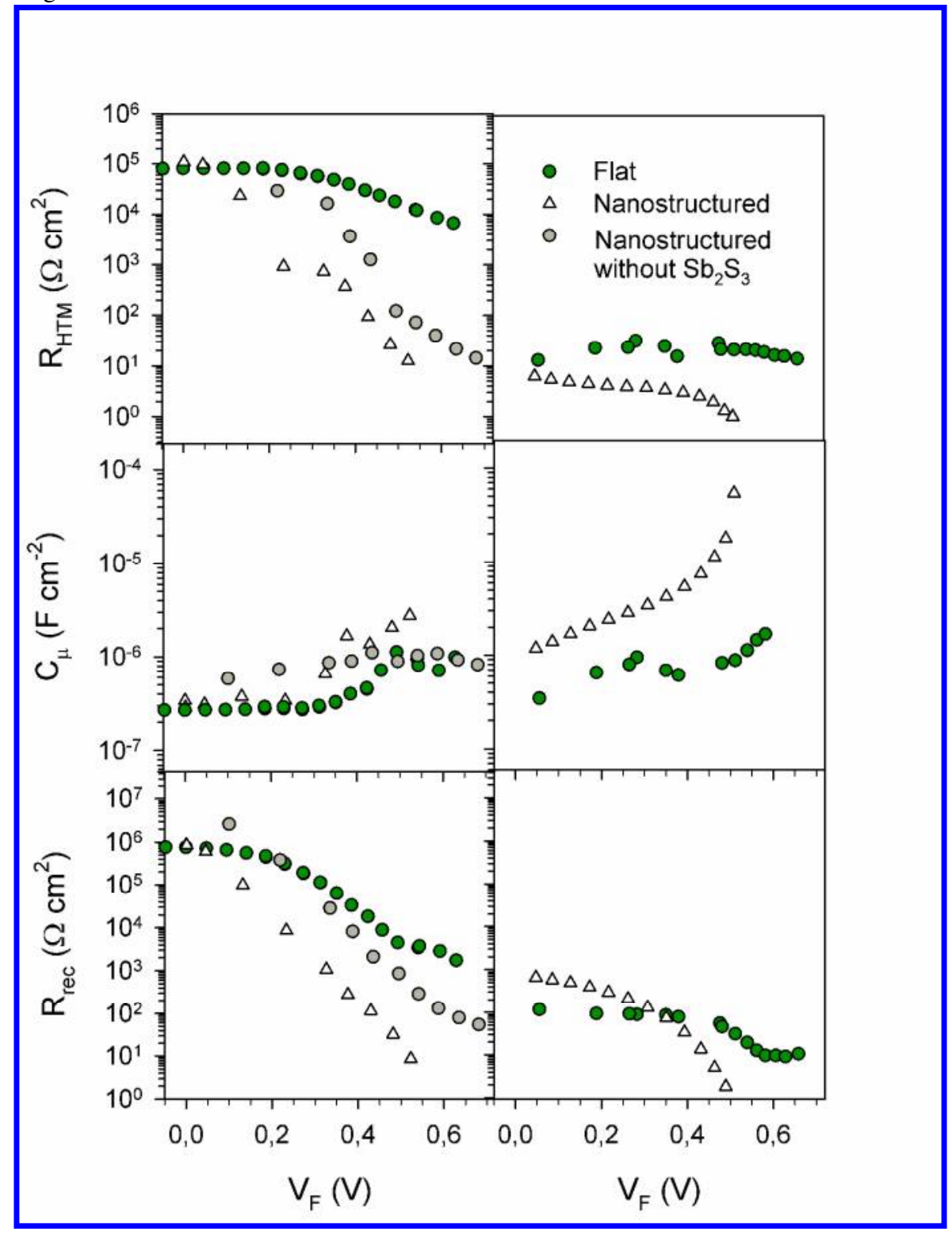


Fig. 6

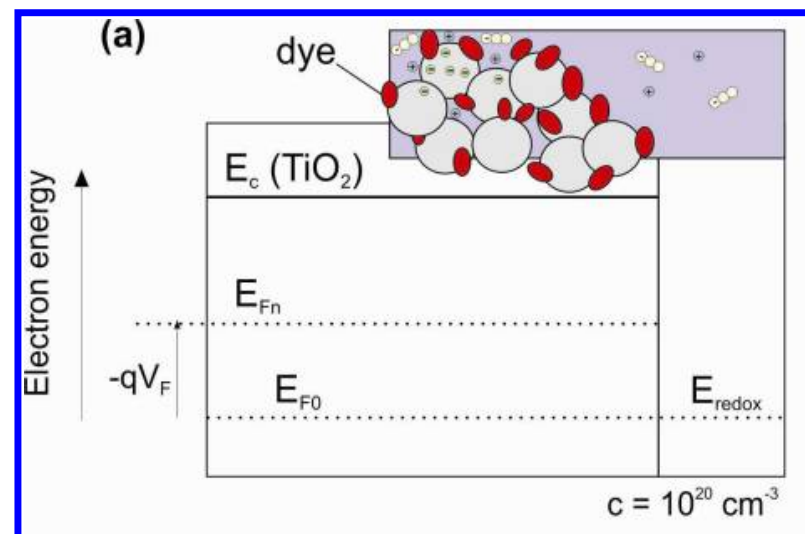

(b)

b) $\quad \mathrm{Sb}_{2} \mathrm{~S}_{3}$

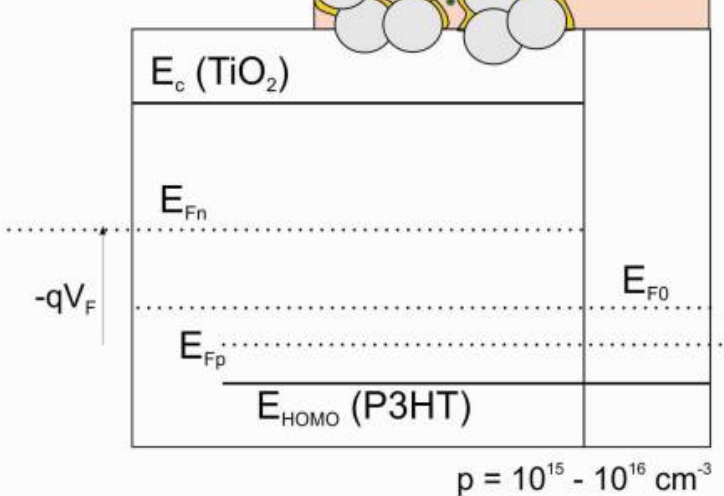

(c)

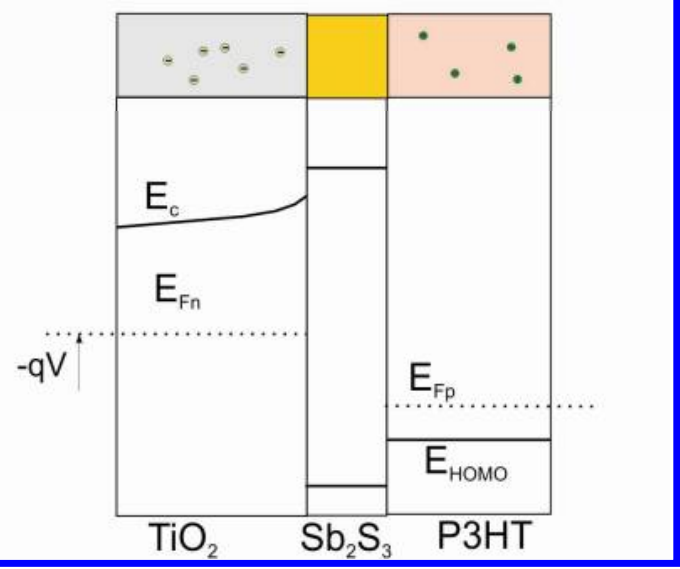


Fig TOC

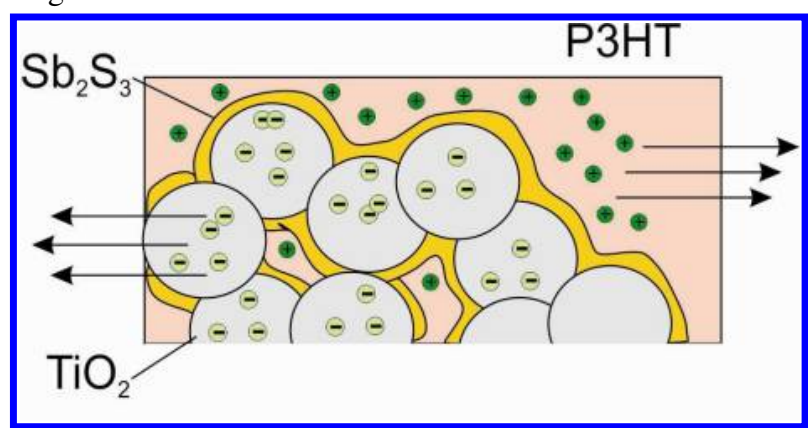

